\title{
A questão ambiental e o adensamento da presença do Exército Brasileiro na Amazônia Legal no final do século XX
}

Environmental issues and the Consolidation of the Army's presence in the Brazilian Amazon in the late twentieth century

Tássio Franchi - Graduado em História pela Universidade Estadual de Londrina (2001) e mestre em História pela Universidade Estadual Paulista Júlio de Mesquita Filho, Franca (2004). Doutorando em Desenvolvimento Sustentável do CDS/UnB. E-mail: tasfranchi@gmail.com

Marcel Bursztyn - Doutor em Desenvolvimento Econômico e Social. Coordenada desde 2000 o Centro de Desenvolvimento Sustentável (CDS) da Universidade de Brasília (UnB), onde tem pesquisa nas áreas de Políticas Públicas, Gestão Ambiental e Ambiente Urbano e Exclusão Social. E-mail: marcel@unb.br

José Augusto Leitão Drummond - Bacharel em Ciências Sociais pela Universidade Federal Fluminense (1975); M. Sc. em Environmental Science - The Evergreen State College (EUA) (1988); Ph. D. em Land Resources - University of Wisconsin, Madison (EUA) (1999). Bolsista de Produtividade Científica 2 do CNPq desde 2009. Professor Associado II da UnB. E-mail: jaldrummond@uol. com.br

\section{Resumo}

A região amazônica ocupa um lugar de destaque quando se pensa em assuntos ligados à questão ambiental. Este artigo aborda a postura e algumas iniciativas de um importante ator institucional presente em toda a Amazônia brasileira, o Exército Brasileiro, relacionandoas historicamente com a ascensão da questão ambiental a partir da década de 1970.

\begin{abstract}
The Amazon region occupies a prominent position in Brazilian and non-Brazilian reflections about issues related to the environment. This article discusses the attitude and some initiatives of a major institutional actor in the region, the Brazilian Army, linking them historically to the rise of environmental issues since the 1970 s.
\end{abstract}

\section{Palavras-chave}

Amazônia. Exército Brasileiro. História ambiental.

\section{Keywords}

Amazon. Brazilian Army. Environmental history. 


\section{INTRODUÇÃO}

Refletir adequadamente sobre a Amazônia Legal exige lidar com a sua importância no plano nacional. Ela abrange nove dos 25 estados do Brasil e corresponde a aproximadamente $61 \%$ do território nacional. A sua importância como reserva de matérias-primas capazes de dar suporte parcial ao desenvolvimento nacional não pode ser ignorada. Não existe quem questione a riqueza mineral, a biodiversidade e o potencial hídrico da região.

As suas potencialidades aguçavam os interesses dos colonizadores portugueses e espanhóis e de viajantes de outras nacionalidades que há séculos passaram pela região e nela tentaram se estabelecer. Diretamente, o Bioma Amazônia (mais extenso do que a Amazônia Legal brasileira) engloba, além dessa grande parcela do Brasil, partes da Bolívia, Colômbia, Equador, Guiana, Peru, Suriname e Venezuela e o território da Guiana Francesa (um estado francês). Além disso, bioma e região têm importância global, na medida em que contribuem para a regulação da emissão de carbono na atmosfera e abrigam um grande número de espécies da fauna e flora. A bacia do rio Amazonas tem cerca de $20 \%$ da água doce do planeta. A sua importância e riqueza ambiental são inquestionáveis. Isso fez com que os governantes brasileiros se preocupassem sistematicamente - inclusive em tempos recentes - em assegurar a soberania do país sobre a parte da Amazônia que está dentro dos limites do território nacional, a Amazônia Legal, que é um recorte territorial mais amplo do que o Bioma Amazônia e a bacia hidrográfica amazônica, mas está limitado pelas fronteiras nacionais.

A presença dos militares na região data do período colonial. Entretanto, devido a fatores históricos, a maior parte da atenção e dos efetivos das Forças Armadas (FFAA) portuguesas e brasileiras sempre esteve direcionada para as fronteiras ao sul do país, região de conflitos graves, como a Guerra do Paraguai. Todavia, à medida que Amazônia ganhou maior destaque no cenário internacional (principalmente por motivos ambientais), nas últimas décadas do século XX, as FFAA brasileiras reposicionaram-se com relação à região, propondo políticas, programas e ações de corte regional ou delas participando. A Amazônia ganhou significativo destaque na Política de Defesa Nacional, definida em 2006, e na Estratégia de Defesa Nacional, definida em 2008.

Este texto tem como objetivo mostrar a evolução do pensamento dos militares e do adensamento de sua presença na região e a sua possível relação com a emergência da questão ambiental global. Para tanto, a exposição foi organizada da seguinte forma: uma breve introdução sobre a ocupação da Amazônia, seguida de um exame das relações entre as FFAA (mais exatamente o Exército Brasileiro) 
e a questão ambiental nos anos 1970, 1980 e 1990 e no início do século XXI. Esse exame desdobra-se em uma discussão analítica da temática. Por último, traçamos algumas considerações e novas indagações sobre o tema.

\section{UMA BREVE HISTÓRIA DA OCUPAÇÃO DA REGIÃO AMAZÔNICA}

Para além de sua pré-história, a região hoje delimitada como Amazônia Legal (que se sobrepõe parcialmente à bacia Amazônica brasileira e à Região Norte do Brasil) tem uma história ligada tanto aos colonizadores portugueses e hispânicos, que atravessaram muitos trechos da região desde os últimos anos do século XV e início do século XVI. O Tratado de Tordesilhas (1494), inadvertidamente, definiu a maior parte da região (ainda desconhecida pelos signatários do tratado) como de domínio espanhol. Os primeiros exploradores espanhóis que passaram pela região foram Vicente Pinzón (1499-1500), Francisco de Orellana e o frei dominicano Gaspar de Carvajal (1540-42), Pedro de Urzua (1560-61) e Don Lope de Aguirre (1559-1561), entre outros (GADELHA, 2007).

Até meados do século XVIII, a colonização da região ficou principalmente a cargo de missionários jesuítas a serviço da Coroa espanhola, como Samuel Fritz, que "por ordem dos reis da Espanha, rege a região dos Cambebas, Tefé e Coari (1686-1704)" (BENCHIMOL, 1992, p. 96). A conquista portuguesa do vale amazônico ocorreu como consequência de várias expedições feitas rio acima, a partir de Belém. Ela foi ratificada pelos tratados de Madrid (1750) e Santo Ildefonso (1777), que definiram parte dos contornos da colônia portuguesa em face das colônias espanholas, tanto ao norte, na região amazônica, quanto ao sul, na região dos Sete Povos das Missões (CORTEZÃO, 2001).

Desde 1772, a Coroa portuguesa dividiu a região em duas unidades administrativas autônomas e distintas, o Estado do Grão-Pará e Rio Negro e o Estado do Maranhão e Piauí. Segundo Márcio Souza, foi após a Independência do Brasil, entre 1823 e 1840, que a "região norte sofre[u] a intervenção política e militar do Império do Brasil. Perde[u] suas lideranças históricas e deix[ou] de ser uma administração colonial autônoma para se transformar numa fronteira econômica" (SOUZA, 2001, p. 92). A ocupação humana da região ainda era incipiente na segunda metade do século XIX, tanto pelas perdas catastróficas de populações indígenas quanto pelo fraco afluxo de colonos europeus em geral, e de portugueses em particular. Weinstein (1998, p. 73) mostra isso ao descrever Manaus, capital da província do Amazonas, como um "entreposto de menor importância, com apenas 5.000 habitantes em 1870". 
A baixa densidade demográfica foi um problema constantemente mencionado nas narrativas sobre a dificuldade de ocupar região, embora nem sempre em conjunção com o reconhecimento da enorme mortandade das populações autóctones. Durante os dois ciclos da borracha (1879/1912 e 1942-1945), dezenas de milhares de migrantes, principalmente dos estados do Nordeste, migraram para a região amazônica para trabalhar na extração do látex da seringueira (Hevea brasiliensis) (DEAN, 1989). Para Benchimol: "Esse foi o começo da explosão urbana na Amazônia. [...] Esse deslocamento serviu para corrigir a extrema dispersão demográfica, criando-se um novo processo de concentração humana ao longo da calha central do Amazonas" (BENCHIMOL, 1992, p. 147). No entanto, Dean, Weinstein, Santos e outros autores mostram que o colapso do preço da borracha na década de 1910 causou uma queda generalizada da população e a retração da ocupação regional.

A partir da segunda metade do século XX e, de forma mais acentuada, no último quartel do século, vários projetos do governo federal incentivaram a migração para a região amazônica. No governo de Juscelino Kubitschek, foi construída a rodovia Belém-Brasília, a primeira a conectar rodoviariamente um trecho da planície amazônica (em torno de Belém) ao restante do Brasil. Os governos militares valiam-se do slogan "Integrar para não entregar." Lançaram vários projetos, como a Zona Franca de Manaus, as rodovias Transamazônica, Cuiabá-Porto Velho e Cuiabá-Santarém, o projeto Carajás, as hidrelétricas de Balbina e Tucuruí, que atraíram pessoas de diversas partes do país. Além dos empreendimentos produtivos e das obras de infraestrutura, os próprios militares foram atores diretos da ocupação e urbanização, desde a década de 1970, ao criar e transferir grandes unidades militares para a região. Ao montar os seus destacamentos de fronteira com vilas militares, eles lançavam as bases de novos núcleos urbanos, que reverteriam a demografia rala, como ressalta Soares:

Esse é o drama que temos de enfrentar o quanto antes e, para enfrentá-lo, é preciso que o governo federal crie, ao longo das fronteiras, estruturas permanentes de colonização; e que os quartéis dos Destacamentos de Fronteiras sejam crisálidas de núcleos populacionais bem organizados, bem providos de resistência orgânica e perfeitamente aparelhados para se transformarem em futuras cidades. Essa é a FRONTEIRA VIVA (SOARES, 1972, p. 170) (destaque no original).

Duas consequências dessas migrações foram a volta do crescimento populacional regional e a urbanização das populações amazônicas. Bem antes da chegada do século XXI, os amazônidas já estavam concentrados nas cidades. 
Bertha Becker mostra-nos que, desde 2000, 70\% da população da Região Norte estava vivendo em núcleos urbanos. Embora as condições de urbanização sejam precárias, Becker sustenta que elas reproduzem os valores dessa urbanização ao tornar a Amazônia uma "floresta urbanizada" (BECKER, 2005, p. 73.).

Essa população urbanizada exerceu pressão cada vez maior sobre o meio ambiente. A relação predatória dos humanos com a natureza e os projetos e políticas governamentais, executados sem avaliação dos impactos ambientais, contribuíram para o surgimento de novos problemas e conflitos socioambientais. "A formação de inúmeros núcleos urbanos [...] nos fez compreender que se tratava de um processo associado ao projeto nacional de rápida modernização da sociedade e do território sob o comando do Estado" (BECKER, 2006, p. 19).

A seguir, será analisada a relação entre esse último período de ocupação da região, com ênfase na presença dos militares do Exército Brasileiro, e a evolução da percepção dos problemas ambientais como questões globais, partindo dos anos 1970 e chegando até meados da primeira década do século XXI.

\section{AS FFAA E A ASCENSÃO DA QUESTÃO AMBIENTAL, DA DÉCADA DE 1970 ATÉ OS DIAS ATUAIS}

Parte-se do seguinte pressuposto: as orientações que guiaram o pensamento da defesa nacional desde a década de 1970 estavam intimamente ligadas à geopolítica internacional e a fatores internos específicos. A hipótese a ser explorada é a de que a emergência da questão ambiental no cenário internacional foi internalizada no discurso da defesa nacional. Ao examinar essa hipótese, pretende-se contribuir para o entendimento do peso que a questão ambiental assumiu no pensamento e nas ações das FFAA, o que talvez as tenha levado a ocupar de maneira mais sistemática a região amazônica desde a década de 1970.

\section{As décadas de 1970 e 1980}

A emergência da questão ambiental não é recente e tem origens bem anteriores à década de 1970. Remontando apenas ao passado recente, merece referência o grupo reunido em torno do economista italiano Aurélio Peccei, que viria a ser conhecido como o Clube de Roma, o qual desde o final dos anos 1960 apontava problemas entre a disponibilidade de recursos naturais essenciais para o desenvolvimento e sua crescente demanda futura e a ideia de que o próprio 
desenvolvimento tecnológico proveria as respostas para tais demandas. O hiato se estabelecia entre a industrialização acelerada e o crescimento populacional e o "escasseamento" dos recursos naturais e a degradação ambiental (CORAZZA, 2005). Com um olhar influenciado pelo viés científico da ecologia, eles alertavam para o modo como os impactos do crescimento demográfico e do consumo ampliado de recursos naturais influíam sobre a capacidade de suporte do ambiente natural, prevendo diversas crises e mesmo um colapso planetário.

Em 1972 foi publicado The Limits to Growth, coordenado por Dennis Meadows e colaboradores. Os autores apontavam que o crescimento contínuo do consumo, baseado no uso ampliado de recursos naturais, movido pelo aumento constante da população mundial, esgotaria as reservas de recursos naturais e poluiria o ambiente para além de sua capacidade de receber poluentes e resíduos. Propunham que a sociedade buscasse a estabilidade, ao invés do crescimento econômico. Para Bursztyn, esse documento é "uma proposta de moratória do crescimento econômico" (1995, p. 57). A ideia de estabilizar o crescimento ou de não crescer não agradou aos países do chamado Terceiro Mundo que, na Conferência das Nações Unidas sobre o Meio Ambiente Humano, realizada em 1972, em Estocolmo (Suécia), levantaram a bandeira do direito ao desenvolvimento.

A preocupação do estado brasileiro com o meio ambiente, como foco novo e específico de regulação pública, ficou clara com a criação da Secretaria Especial do Meio Ambiente (SEMA), em 1973. Ela nasceu dos compromissos que o país assumiu na Conferência de Estocolmo. Surgiu no momento em que se iniciava em, escala nacional e global, a institucionalização de práticas voltadas a garantir a qualidade ambiental.

O chamado "choque do petróleo", iniciado em 1973, serviu de alerta aos estados nacionais para a importância de controlar e usar de forma racional os recursos energéticos e de definir estratégias visando reduzir a dependência de recursos naturais importados. Uma resposta brasileira à crise de fornecimento do petróleo foi a criação do Proálcool, em 1975, com o objetivo de atender a uma parte da demanda interna e externa de combustíveis automotivos. A temática dos recursos energéticos não renováveis, principalmente depois do chamado segundo choque do petróleo, em 1979, permeou o debate ambiental internacional, que chegou à década de 1980 sob a influência do medo do esgotamento e da destruição de importantes recursos naturais e da necessidade de regular e proteger esses recursos. É nesse momento que a Amazônia começa a aparecer perante a opinião pública nacional e internacional com imagens variadas, mas todas de colorido ambiental - "pulmão do mundo", repositório de biodiversidade, grande reserva de 
água, sede de enormes florestas tropicais e de outros recursos naturais, merecedora de proteção e preservação. São deste período declarações que apontavam para a necessidade de ingerência internacional sobre a região. Um exemplo amplamente citado por autores civis e militares brasileiros foi o trecho de um discurso do presidente francês François Miterrand, em 1989: “O Brasil precisa aceitar uma soberania relativa sobre a Amazônia” (BENAT'TI, 2007, p. 27).

O termo "direito de ingerência" tem as suas origens na assistência humanitária internacional e no atendimento aos direitos humanos (ALVES, 2002). Para alguns autores, o marco histórico do surgimento do direito de ingerência internacional é o fim da Guerra Fria. Entretanto, sob a capa humanitária da ingerência internacional, podem estar interesses não explícitos e novos contornos ambientais, desde que se percebeu o meio ambiente como um todo integrado (CERVO, 2002; TILIO NETO, 2003). Todavia, para os militares brasileiros, a faceta mais preocupante da ingerência proposta está na relativização da soberania nacional brasileira sobre a região amazônica (MARTINS FILHO, 2001). Essa perspectiva acendeu a luz vermelha para as esferas militares nacionais, como será argumentado a seguir.

Em 1987 foi publicado o documento Our Common Future (ONU, 1987), um relatório contendo as conclusões da Comissão Brundtland. Ele serviria de base aos debates na Conferência das Nações Unidas para o Meio Ambiente e o Desenvolvimento (também conhecida como Rio-92 ou Eco-92), realizada em 1992. Nesse documento, emerge o conceito de desenvolvimento sustentável, que ainda se limitava à noção de que as relações entre os humanos e o meio ambiente deveriam ocorrer de forma a que se atendesse às necessidades das gerações atuais, sem comprometer o atendimento às necessidades das gerações futuras. Desde então, inúmeros autores debruçaram-se sobre o conceito, que hoje incorpora uma série de críticas e se constrói de forma mais ou menos complexa, variando de autor para autor. De uma maneira geral, o termo está associado ao denominador comum expresso por três ideias básicas: viabilidade econômica, justiça social e equilíbrio ecológico.

No cenário internacional das décadas de 1970 e 1980, vivia-se ainda sob a égide do mundo bipolar e da disputa entre o capitalismo e o comunismo como modelos político-sociais. A Guerra Fria entre EUA e URSS, travada desde 1946, arrastava consigo diversos atores. A tensão Leste-Oeste materializava-se em conflitos, como a Guerra do Vietnã (1965-1975). Todavia, desde a conferência de Bandung (Indonésia), em 1955, um grupo de 29 países denunciava a existência de outra tensão, a Norte-Sul, que opunha os países ricos do Norte aos países pobres do Sul. Em 1961, esses países acabaram compondo um bloco conhecido como 
o Terceiro Mundo ou os não alinhados (HOBSBAWM, 1995). Embora o Brasil fizesse parte desse grupo, as orientações emanadas da esfera castrense colocavam o país no bloco dos países que percebiam o comunismo como o inimigo maior, o que diluiu uma postura de pertencimento do Brasil ao Sul. Essa postura ficou clara na expressão de um dos norteadores do pensamento do regime militar brasileiro, Golbery do Couto e Silva:

O Brasil é também uma nação que, pela sua origem cristã, valores democráticos e liberais que substanciam a cultura ainda em germe nesta fronteira em expansão, integra o Mundo do Ocidente, hoje, como nunca, ameaçado também pelo dinamismo imperialista e o imperialismo ideológico da civilização materialista que tem seu fulcro esteado no coração maciço da Eurásia. E nossa Geopolítica terá de ser, por conseguinte, uma Geopolítica consciente e decididamente partícipe da Geoestratégia defensiva da Civilização Ocidental, a cujo destino temos os nossos indissoluvelmente ligados, quer o queiramos ou não (SILVA, 1981, p. 170).

Silva era claro quanto ao posicionamento que a nação brasileira deveria assumir com relação à Guerra Fria. O Brasil estava "indissoluvelmente" ligado ao bloco dos países sob a influência direta dos EUA. Além do inimigo externo, materializado pela URSS e pelos outros países do Segundo Mundo (a esfera de influência soviética), havia os inimigos internos. Isto assumiu uma expressão mais explícita, segundo Borges (2003), na doutrina de segurança nacional - DSN:

Criada na época da guerra fria, nascida do antagonismo leste-oeste, a Doutrina de Segurança Nacional [...] é a manifestação de uma ideologia que repousa sobre uma concepção de guerra permanente e total entre o comunismo e os países ocidentais. [...] a guerra é total, no sentido de que o antagonismo dominante se encontra, igualmente, nas fronteiras. Portanto, a agressão pode vir tanto do exterior (comunismo internacional) quanto do interior (inimigo interno) (BORGES, 2003, p. 24) (grifos nossos).

Nesse momento ainda havia uma concentração regional dos efetivos das FFAA brasileiras que, historicamente, estavam voltadas para e instaladas no Cone Sul. A região cisplatina, palco do último conflito armado externo de que o Brasil participou maciçamente, a guerra contra o Paraguai (1864-1870), passou a perder importância estratégica com a ascensão da questão ambiental e o destaque que a Amazônia ganhou dentro dela. Durante a década de 1980, a Guerra das Malvinas, entre Argentina e Grã-Bretanha, desacreditou perante os olhos das FFAA brasileiras a capacidade militar da Argentina, tida até então como principal oponente do Brasil no subcontinente sul-americano. Além do mais, uma série de acordos de cooperação em diversas áreas promoveu o estreitamento de laços entre os dois países. O Tratado de Assunção, assinado entre Brasil, Argentina, Paraguai e Uruguai, em 1991, nasceu de uma série de conversações e tratados 
menores, multi e bilaterais, assinados durante as décadas de 1970 e 1980. Ele é o mais emblemático, pois demonstra o grau de estreitamento de laços entre os países da região do Cone Sul para a criação de um mercado comum, o Mercosul. Com a fronteira sulina estabilizada, as atenções do Brasil voltam-se para a sua Região Norte que, até então, havia tido pouca importância nas estratégias militares e, por consequência, na alocação de bases, portos, aeroportos, efetivos e recursos militares.

A área que formaria a Amazônia Legal tinha, na década de 1950, um contingente militar fixo de apenas cerca de 1.000 pessoas; em 1989, crescera para cerca de 8.000; em 2007, chegou a cerca de 25.000, cifra inferior a 25\% do efetivo total das FFAA. Embora crescente, esse contingente relativamente pequeno estava incumbido de defender mais de $60 \%$ do território nacional, cerca de 5,2 milhões $\mathrm{km}^{2}$ (PERI, 2007).

Até 1976, a defesa da Amazônia Legal cabia a um Grupamento de Elementos de Fronteira, sediado em Manaus desde 1948. Devido a reestruturações do Exército, ele foi transferido para Belém, em 1957, e transferido de volta para Manaus, onde viria a se tornar, em 1969, o Comando Militar da Amazônia.

Até a década de 1990, havia apenas duas brigadas de infantaria do Exército sediadas na região. Os seus efetivos espalhavam-se por alguns municípios, onde existiam unidades menores, como batalhões e pelotões especiais de fronteira, subordinados às brigadas e ao Comando Militar da Amazônia (CMA). Do ponto de vista histórico, somente foram criadas grandes unidades militares na região da Amazônia Legal a partir de meados da década de 1970. A primeira, a 23 Brigada de Infantaria de Selva, sediada em Marabá-PA, foi criada em 1976, na esteira da Guerrilha do Araguaia, combatida por tropas trazidas de outros estados (STUDART, 2006). Essa brigada tem a particularidade de ter sido assentada junto ao primeiro eixo rodoviário de integração da Amazônia Legal ao restante do país, a rodovia Belém-Brasilia, e próxima a grandes investimentos governamentais de desenvolvimento, como o complexo de mineração de Carajás e a usina hidrelétrica de Tucuruí. Em 1980 foi criada a 17ª Brigada de Infantaria de Selva, sediada em Porto Velho-RO. O Estado de Rondônia faz fronteira com a Bolívia e é, ainda hoje, um dos eixos integradores da Região Norte, contando com rodovias que ligam Rio Branco-AC a Brasília-DF, passando por Cuiabá-MT (THÉRY, 2005).

A partir de 1985, o Brasil entrou numa fase de redemocratização, mas os militares mantiveram forte influência sobre diversas pastas do governo do presidente José Sarney (MARQUES, 2001). Com efeito, o Programa Calha Norte (PCN) foi idealizado durante os governos de Ernesto Geisel (1974-1979) e João Batista Figueiredo (1979-1985) e foi executado durante o governo Sarney. O PCN/1985 foi uma primeira tentativa governamental ampla de associar o papel 
dos militares à proteção da Amazônia, como fica claro no seguinte trecho do discurso do presidente José Sarney na XLIV Sessão Ordinária da Assembleia Geral da Organização das Nações Unidas, em 1989:

Duas grandes questões devem igualmente ser objeto da nossa preocupação prioritária: a proteção ambiental e o combate ao tráfico e uso de drogas. (...) Nossa política, nesse campo, é enérgica e profilática. Há quatro anos, com o "Programa Calha Norte do Amazonas", ocupamos e fiscalizamos nossas extensas fronteiras para assistir às populações locais e impedir a entrada de traficantes perseguidos de outros países (COSTA, 1995, p. 500).

Entre 1985 e 1999, o PCN foi responsável pela construção de quartéis de brigadas (2), pelotões de fronteira (8), aeródromos (20), trechos de rodovias (BR-307 e BR-156), hospitais (2), centros de saúde em terras indígenas (15), poços artesianos, escolas e salas de aula, e pelo apoio à demarcação de terras indígenas (36). Durante os governos Fernando Collor, Itamar Franco e Fernando Henrique Cardoso, essas ações continuaram e o orçamento do PCN foi incluído no Plano Plurianual (PPA) de 2000-2003 do governo federal. Em 2004, sua área de atuação abrangia 2.186.252 km² da Amazônia Legal (SILVA, 2007; SILVA, 2008). O PCN seguiu investindo na construção e manutenção de infraestrutura civil e militar, dando ao Ministério da Defesa uma visibilidade maior junto às populações locais, “já que a construção de infraestrutura é sempre valorizada” (SILVA, 2007, p. 62). Atualmente, o PCN segue como um dos principais programas do Ministério da Defesa para a Região Norte, com duas linhas de ação: soberania e desenvolvimento.

\section{A DÉCADA DE 1990 E OS PRIMEIROS ANOS DO SÉCULO XXI}

Em 1992, o Brasil foi sede da Conferência das Nações Unidas para o Meio Ambiente e o Desenvolvimento. O evento foi palco de um consenso em torno do conceito de desenvolvimento sustentável, incorporado de inúmeras formas ao discurso de governos, pensadores e organizações, muitas vezes sem a devida crítica ou o conhecimento de suas reais dimensões. O ano de 1992 foi marcado por uma série de eventos na área ambiental no Brasil. O Ministério do Meio Ambiente, que antes era apenas uma secretaria ligada à Presidência da República, retomou, durante o governo Itamar Franco, o status de ministério. No encontro foram lançadas a Agenda 21, a Convenção da Diversidade Biológica e a Convenção de Mudanças Climáticas. Ficou evidente o alerta para a necessidade de se criar modelos de desenvolvimento e estimular mudanças de comportamento que garantissem a preservação do planeta e o papel importante que o Brasil poderia 
assumir nesse novo contexto, inclusive pelo fato de ter soberania sobre a maior parte da ambientalmente valorizada Amazônia.

No Brasil, ganhou maior vulto o esforço no sentido de reverter as críticas feitas desde a década anterior à degradação ambiental, em especial na Amazônia. Entre 1990 e 1991 foi instalado o sistema SIVAM/SIPAM, foi dado novo alento ao Projeto Calha Norte e foi retomada a transferência de grandes unidades militares para a Amazônia. A 1 a Brigada de Infantaria de Selva foi transferida de PetrópolisRJ para Boa Vista-RR, em 1991. A transferência da 16 B Brigada de Infantaria de Selva, de Santo Ângelo-RS para Tefé-AM, em 1993, deixou ainda mais clara a mudança da prioridade da defesa nacional, do Cone Sul para a Região Norte.

Em 1995, no início do governo Fernando Henrique Cardoso, é lançado o documento intitulado Política de Defesa Nacional - 1996 (MINISTÉRIO DA DEFESA, 1996). Ele indicava as prioridades e as diretrizes a serem seguidas pelas FFAA. Esse documento foi a base sobre a qual se formulou o atual documento da defesa nacional, a Política de Defesa Nacional-2006, que será analisado de forma mais detalhada a seguir. De forma geral, durante toda a década de 1990 houve uma retração da participação das organizações militares no orçamento nacional. Em finais da década de 1980, ela atingia mais de $2 \%$ do PIB, mas caiu para 1,2\% em 1991 e 1992. Um breve aumento ocorreu no final da década. Na entrada do novo milênio, em 2001, o orçamento voltou ao patamar de $2 \%$, caindo novamente nos anos seguintes. A retração do orçamento da defesa foi um dos fatores que contribuiu para paralisar as transferências de outras grandes unidades para a Amazônia (PESCE, 2006). Todavia, mais de dez anos depois, com o governo Lula, o processo de adensamento da presença dos militares na região se revigorou. Em 2004, a $2^{a}$ Brigada de Infantaria de Selva foi transferida do Rio de Janeiro para São Gabriel da Cachoeira-AM. (BRASIL, 2004.). Os seus $3^{\circ}$ e $56^{\circ}$ Batalhões de Infantaria deverão ser instalados, até 2010, em Santa Isabel do Rio Negro e Barcelos, e devem ser criados novos Pelotões Especiais de Fronteiras.

Assim, em 2004 o Exército Brasileiro passou a contar com um efetivo de aproximadamente 22 mil homens na Amazônia Legal. Somados aos efetivos das outras duas forças armadas (Marinha e Aeronáutica), o CMA totaliza aproximadamente 28 mil homens, 3,5 vezes mais do que nos anos 1980. Nesse mesmo período, a população da Amazônia Legal cresceu apenas na proporção de 1 para 1,5 , atestando um crescimento mais do que proporcional ao dos contingentes militares.

Seria a ascensão da questão ambiental o pano de fundo para esse adensamento da presença militar na região? Depois da Primeira Guerra do Golfo, alguns membros das FFAA já estavam sensíveis ao peso da questão ambiental 
nas mudanças geopolíticas internacionais. O medo de uma intervenção militar estrangeira na Amazônia estava em parte associado à questão ambiental, como mostra a posição assumida pelo vice-almirante Armando Amorim Ferreira Vidigal:

Os princípios básicos que regeram as relações internacionais até a Guerra do Golfo - não-intervenção e autodeterminação [grifado no original] - são, no mundo atual, ignorados pelas grandes potências que pregam a intervenção, sempre que, na sua exclusiva avaliação, há risco para a democracia, violação grave dos direitos humanos, possibilidades de tragédia ecológica [grifos nossos], ameaça à paz, ou qualquer outra nobre razão que os idealistas de plantão saberão achar no momento oportuno (VIDIGAL apud MARTINS FILHO, 2001, p. 262).

A Primeira Guerra do Golfo deixava claro, para parte dos pensadores castrenses, que algo havia mudado na ordem internacional e que a questão ambiental deveria ser levada em conta para não se tornar um pretexto para uma intervenção estrangeira.

Autores como Brand e Görg apontam que a questão da ingerência dos países desenvolvidos nos recursos naturais dos países não desenvolvidos gira em torno, não de uma preocupação sobre o meio ambiente em si, mas sim sobre quem pode usar tais recursos (BRAND; GÖRG, 2003). O paralelo entre as perspectivas de Brand e Görg e a visão do vice-almirante Vidigal deixa evidente que a preocupação real dos militares brasileiros não é com o meio ambiente em si, mas sim com o acesso aos recursos naturais e ao poder de decisão sobre eles. Para os militares brasileiros, o tema passava a ser " [...] defesa da soberania nacional, diante de um mundo onde velhos princípios da política internacional eram abandonados e no qual o realismo das grandes potências aparecia disfarçado de idealismo universalista" (MARTINS FILHO, 2001, p. 262).

Vale examinar um dos documentos norteadores das ações dos militares na Amazônia. A mencionada Política de Defesa Nacional de 2006 versa sobre o papel prioritário da defesa da região amazônica, pelo fato de se tratar de uma importante fonte de recursos/riquezas naturais, conforme fica evidente em dois de seus itens:

4.3 O planejamento da defesa inclui todas as regiões e, em particular, as áreas vitais onde se encontra maior concentração de poder político e econômico. Complementarmente, prioriza a Amazônia e o Atlântico Sul pela riqueza de recursos e vulnerabilidade de acesso pelas fronteiras terrestres e marítimas.

4.4 A Amazônia brasileira, com seu grande potencial de riquezas minerais e de biodiversidade, é foco da atenção internacional. (...) O adensamento da presença do Estado, e em particular das Forças Armadas, ao longo das nossas fronteiras, é condição necessária para conquista dos objetivos de estabilização e desenvolvimento integrado da Amazônia (MINISTÉRIO DA DEFESA, 2006) (grifos nossos). 
A PDN-2006 assume de forma veemente o discurso ambientalista como razão estratégica e de segurança nacional, paralelamente à não menos relevante referência ao desenvolvimento. Convém, entretanto, voltar a um ponto anterior da referida política:

1.6. A implementação de uma política de defesa sustentável, voltada para a paulatina modernização da capacidade de auto-proteção, depende da construção de um modelo de desenvolvimento que fortaleça a democracia, reduza as desigualdades sociais e os desequilíbrios regionais e compatibilize as prioridades nos campos político, social, econômico e militar, com as necessidades de defesa e de ação diplomática (MINISTÉRIO DA DEFESA, 2006) (grifos nossos).

O documento da PDN-2006 reporta-se, portanto, a dois pilares do conceito de desenvolvimento sustentável, nos moldes estabelecidos no Relatório Brundtland, de 1987. Contudo, omite o eixo "ecologicamente correto". O argumento ambiental serve de pano de fundo para justificar o aumento da presença militar, como fica claro no trecho a seguir:

Ela [a estratégia do Programa Calha Norte] é baseada principalmente na implantação e ampliação de unidades militares da Marinha, do Exército e da Força Aérea, como também no apoio aos pólos irradiadores do desenvolvimento social sustentável e ambientalmente correto na região amazônica (MINISTÉRIO DA DEFESA, 2006) (grifos nossos).

O discurso do PCN em 2009 é bem claro e está recheado de outros exemplos. Mas, fica a incômoda pergunta: o que seria, na prática, uma "defesa sustentável"? No Brasil, as FFAA adotam políticas de gestão ambiental específicas a cada uma delas. A Marinha do Brasil segue a norma ISO 14001 para a gestão ambiental da Armada. Ela tem, inclusive, funções de órgão da fiscalização do meio ambiente aquático (Lei Complementar 117/2004 e Lei no. 9966/2000; e art. 91 $\int 1^{\circ} \mathrm{da}$ Constituição Brasileira-1988). O Exército Brasileiro publicou, em 2001, duas portarias relevantes, com os seguintes títulos: "Política de Gestão Ambiental do EB" (Portaria n". 570, 18 de julho de 2001) e "Diretriz Estratégica de Gestão Ambiental do EB" (Portaria n. 571, 18 de julho de 2001). Esses documentos demonstram a preocupação com a adequação a normas e à legislação ambiental. Eles responderam ao crescimento da importância da questão ambiental no cenário internacional, como podemos ler no tópico "Premissas Básicas", da mencionada Portaria no. 571:

A gestão ambiental assume importância cada vez maior no cenário mundial, tornando imprescindível, portanto, o zelo e diretrizes vigentes, quando da realização de atividades e empreendimentos militares, principalmente dos passíveis de causar degradação ao meio ambiente (EXÉRCITO BRASILEIRO, 2001) (grifos nossos). 
A relação explícita argumentada entre o "cenário mundial" e o fato de que o Exército deve ter como "imprescindível o zelo pela fiel observância de toda a legislação ambiental" evidencia a importância que a questão ambiental assumiu para o EB no início do século atual. Essa preocupação foi mantida por meio da Portaria $\mathrm{n}^{\circ}$. 386, de 29 de junho de 2008, que aprovou o sistema de gestão ambiental do EB. Posteriormente, uma nova portaria (n. 1.138, de 22 de novembro de 2010) aprovou a Política de Gestão Ambiental do Exército em vigor. Um link na página oficial do Exército na Internet disponibiliza documentos, palestras e dados sobre as ações ligadas ao meio ambiente em todo o território nacional.

\section{A DISTRIBUIÇÃO DAS GRANDES UNIDADES DO EXÉRCITO NA AMAZÔNIA}

Nas décadas de 1970 e 1980, os grandes projetos governamentais de integração da região e o medo de movimentos comunistas e de opositores internos ao regime podem ter influenciado a criação das Brigadas de Marabá e Porto Velho. Coincidentemente ou não, elas estão situadas dentro do que hoje é chamado de "arco do desmatamento", uma vasta parcela da Amazônia cujos novos polos de colonização exercem pressão sobre a floresta, causando desmatamentos e queimadas, em ligação com a pecuária extensiva, a agricultura e a extração de madeira (MACHADO, 2009). Após os anos 1980, e principalmente nos anos 1990, as mudanças na geopolítica internacional e o fato de a região amazônica ter ganhado visibilidade no debate ambiental colocaram a região Norte em destaque no pensamento estratégico militar brasileiro (MARQUES, 2001). Essa mudança traduziu-se no adensamento dos efetivos na região e na criação da PDN-1996, na qual a Amazônia aparece como área prioritária para a defesa nacional.

A transferência de duas brigadas, sediadas nas regiões Sul e Sudeste, para a Amazônia é emblemática do arrefecimento das tensões no Cone Sul e da emergência da região amazônica como foco de atuação das FFAA. As brigadas realocadas para Tefé (1993) e Boa Vista (1991) estão estrategicamente situadas. A primeira localiza-se sobre a interseção dos principais afluentes do Solimões, principal via de acesso fluvial ao interior do Brasil a partir dos países andinos, e está em contato direto com a fronteira colombiana, área de atuação do movimento guerrilheiro Forças Armadas Revolucionárias da Colômbia (FARC). Vale lembrar que, em 26 de fevereiro de 1991, um ataque das FARC a um Pelotão de Fronteira do Exército Brasileiro, situado às margens do rio Traíra, no município de TabatingaAM, deixou três soldados brasileiros mortos e nove feridos, além de uma série 
de armas roubadas, mostrando a fragilidade do Exército Brasileiro nas fronteiras mais ocidentais do país (ZAVERUCHA, 2000). A $2^{\text {a }}$ Brigada, em Boa Vista, está voltada para a porta do país para os países ao largo do Caribe. Serve também de suporte logístico para os pelotões de fronteira que guardam o extremo norte do país, no arco que vai da "cabeça do cachorro", no Amazonas, até Oiapoque, no Amapá. Ambas as unidades podem ser pensadas também como um claro reflexo do programa Calha Norte e das projeções feitas na última metade da década de 1980, quando o discurso de internacionalização da Amazônia havia sido levantado.

Em 2004, a instalação da $2^{\text {a }}$ Brigada de Infantaria de Selva em São Gabriel da Cachoeira aumentou e fortaleceu o contingente da região da "cabeça do cachorro". Todavia, em um contexto diferente, pois já haviam se passado oito anos depois da publicação da PDN-1996, texto em que a Amazônia figura como área prioritária para a defesa do país. Concomitante à função de defesa, o Exército busca ocupar e desenvolver a região, objetivos que ficam claros ao lermos a missão do $5^{\circ}$ Batalhão de Infantaria de Selva (componente da $2^{\text {a }} \mathrm{Bda}$ de InfSl): "O objetivo maior da unidade é a ocupação, vivificação e desenvolvimento do vazio demográfico que caracteriza a região" (EXÉRCITO BRASILEIRO/5 BIS, 2011). Para isso, os militares empenham-se em ações, como: a construção e manutenção de obras de infraestrutura (rodovias BR-319 e BR-174), trabalho feito pelos batalhões de engenharia e construção; os atendimentos médico-odontológicos às populações ribeirinhas, feito em Ações Cívico-Sociais (ACISO); uma postura mais atuante em conjunto com outras entidades federais, como o IBAMA e a Polícia Federal, para coibir atividades ilícitas na região, a exemplo do garimpo, da extração ilegal de madeira, entre outras. Tal como o Exército, as outras Forças também possuem um largo histórico ligado à região. O papel da Aeronáutica remonta às suas origens em 1941, quando foi criada para atender à necessidade de enviar homens ao front italiano, mas, paralelamente, assumiu as funções do Correio Áereo Nacional (CAN), com voos regulares para comunidades remotas da Amazônia, que o norte-americano John Hemming, entre outros, classificou como admiráveis (HEMMING, 2008). Ainda hoje as aeronaves da Força Aérea prestam apoio a comunidades isoladas e entidades governamentais por meio de transporte de pessoal, suprimentos e evacuações aeromédicas. De modo semelhante às ações de ACISO do Exército, a Marinha do Brasil desenvolve a Operação de Assistência Hospitalar às Populações Ribeirinhas (ASSHOP), que leva atendimento médicoodontológico às comunidades menos desenvolvidas, utilizando quatro Navios de Assistência Hospitalar (NAsH).

Espacialmente, o Comando Militar da Amazônia (CMA), sediado em Manaus, está no centro da região da Amazônia brasileira. As sedes das suas brigadas 
estão distribuídas de forma a cobrir as principais vias de acesso ao país (fluviais e terrestres) e a fornecer apoio logístico rápido aos Pelotões Especiais de Fronteira (Mapa I). Anos depois, como demonstraram os documentos e as ações das esferas castrenses, a região amazônica manteve o seu destaque na PDN-2006, conforme atesta o crescimento dos efetivos ali sediados.

Mapa 1 - Municípios-sede das Brigadas de Infantaria de Selva do Exército na Amazônia (com datas de instalação) e sede do Comando Militar da Amazônia.

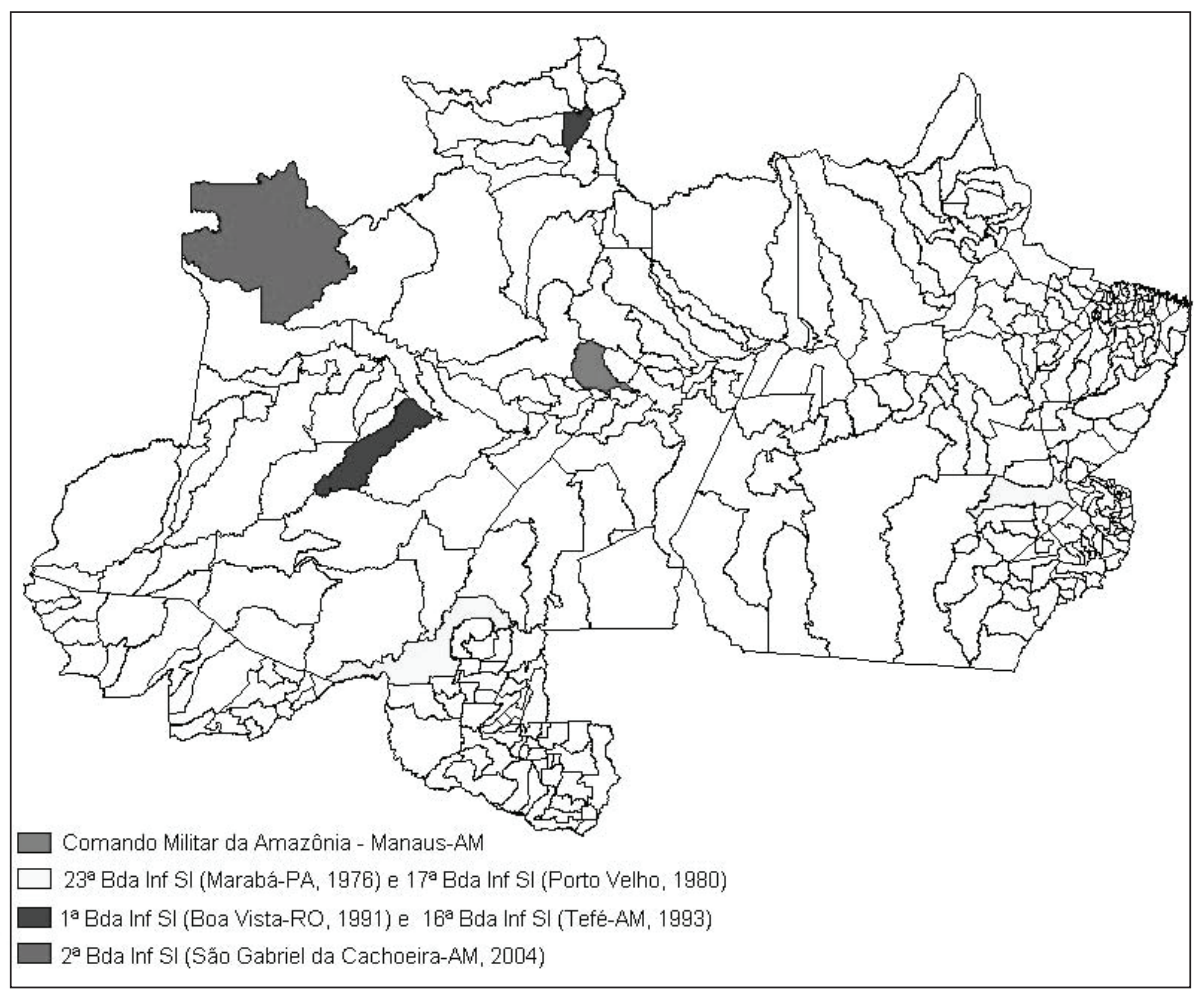

O ideal de ocupar e desenvolver a região não é novo. Durante os anos em que estiveram à frente do poder executivo (1964-1985), os militares desenvolveram vários projetos, tentaram desenvolver e vivificar a Região Norte, alguns com grandes passivos ambientais, como a represa da UHE de Balbina e a ocupação desordenada de áreas no Pará e Rondônia. Todavia, a região permanecia em segundo plano, se observada sob a ótica da presença efetiva de forças capazes de defendê-la. Somente com o aumento da preocupação com a preservação ambiental, em virtude do destaque global que ganhou a floresta amazônica, é que os militares passam a incrementar de modo sistemático seus efetivos na região. 
Toda essa postura vem acompanhada, desde 2001, de uma normatização da gestão ambiental e, após 2010, de modo mais efetivo com a criação da Seção de Meio Ambiente (SMA), ligada à Diretoria de Patrimônio do Exército (D Patr). Envolvidas em ações que vão da educação ambiental no sistema de ensino do Exército até a recuperação de áreas degradadas devido ao uso para fins de treinamento, a Seção de Meio Ambiente do Exército busca enquadrar a instituição dentro da legislação ambiental vigente no país. Aos olhos desavisados, pode parecer demasiado tarde o surgimento de uma organização específica dentro do quadro da Força Terrestre tratando especificamente do meio ambiente; todavia sua presença pode ser notada na preocupação de altos oficiais do período anterior, sendo tardia apenas sua materialização em uma seção provida de efetivos.

\section{CONSIDERAÇÕES FINAIS}

O objetivo deste texto foi o de mostrar a existência de uma relação entre a ascensão da questão ambiental, o pensamento estratégico militar e o adensamento da presença dos militares, em especial do Exército Brasileiro, na região amazônica brasileira, desde a década de 1970 até meados da primeira década do século XXI. Como foi visto, nos anos 1970 e 1980, as grandes unidades militares instaladas na região seguiram os traçados dos eixos integradores ou se mantiveram próximas a grandes projetos de desenvolvimento, ajudando, em consonância com a ideologia predominante, a “integrar para não entregar". As críticas ambientais internacionais ao Brasil apareciam fortemente nesse período. Na década de 1990, o governo e os militares do Exército Brasileiro deram respostas contundentes à ascensão da questão ambiental e da atenção internacional sobre a Amazônia, instalando duas grandes unidades militares na região. A edição do documento da Política de Defesa Nacional-1996, no qual a região figurava como área prioritária, dá publicidade oficial à postura militar no tocante à região. A importância da Amazônia foi reafirmada nos novos textos, o da Política de Defesa Nacional, publicado em 2006, e o da Estratégia de Defesa Nacional (2008). No âmbito da Força Aérea, os programas SIVAM/SIPAM, que geram informações usadas para a proteção ambiental e para o combate a atividades ilícitas de contrabando no espaço aéreo brasileiro, demonstram a preocupação com a defesa, aliada à questão ambiental (RODRIGUES, 2002).

Conclui-se que as diretrizes das FFAA foram sensíveis à ascensão das questões ambientais no cenário internacional, no final do século $\mathrm{XX}$, e que a importância da região amazônica para o Brasil foi explicitada em documentos 
públicos das FFAA, nos quais ela aparece como área prioritária. Entende-se que a criação e a transferência de grandes unidades militares do Exército Brasileiro para a Amazônia atenderam a uma antiga necessidade de ocupar e defender a região e suas riquezas.

Mesmo com o incremento do efetivo nas últimas décadas, proporcionalmente menos de $25 \%$ dos militares estão sediados na região amazônica, que cobre mais de $50 \%$ do território nacional em uma fronteira extensa e aparentemente permeável.

Todavia, alguns questionamentos são pertinentes. Se a Amazônia Legal representa mais de $60 \%$ do território nacional, por que não sedia nem $25 \%$ do contingente das FFAA? A maior presença das FFAA poderia contribuir para a defesa e mesmo para o desenvolvimento da região. O crescimento da presença militar na região e a ampliação das ações de caráter subsidiário contribuiriam para o bem-estar das populações menos favorecidas da região.

Os impactos que a ocupação pode trazer para a região, entretanto, ainda não são evidentes. É preciso avaliar se a presença das FFAA, em especial do EB, como vetor de ocupação e desenvolvimento, está funcionando. É preciso pensar, para além da defesa do território, a real participação das FFAA no desenvolvimento sustentável da região. Que indicadores socioambientais podem auxiliar a identificar e analisar as consequências da implantação de centenas de militares em localidades isoladas da floresta? Estas são algumas questões que merecem ser deixadas em aberto, de forma a provocar um debate sobre o papel dos diversos atores presentes no desenvolvimento da Amazônia, dentre os quais as FFAA.

\section{REFERÊNCIAS}

ALVES, J. A. Lindgren. O contrário dos direitos humanos (explicitando Zizek). Lua Nova, São Paulo, n. 55-56, 2002. Disponível em: <http://www.scielo.br/ pdf/\%0D/ln/n55-56/a05n5556.pdf>. Acesso em: 11 set. 2009.

BECKER, B. K. Geopolítica da Amazônia. Estudos Avançados: Dossiê Amazônia Brasileira, São Paulo, n. 53, jan./abr. 2005.

BECKER, B. K. Amazônia: geopolítica na virada do III milênio. Rio de Janeiro: Garamond, 2006.

BENATTI, J. H. Internacionalização da Amazônia e a questão ambiental: o direito das populações tradicionais e indígenas à terra. Revista Amazônia Legal de estudos socio-jurídico-ambientais, Cuiabá, v. 1, n. 1, p. 23-39, jan./jun. 2007. 
BENCHIMOL, Sl. Amazônia: a guerra na floresta. Rio de Janeiro: Civilização Brasileira, 1992.

BORGES, N. A Doutrina de Segurança Nacional e os governos militares. In: FERREIRA, J.; DELGADO, L. A. N. O Brasil Republicano: o tempo da ditadura, regime militar e movimentos sociais em fins do século XX. Rio de Janeiro: Civilização Brasileira, 2003. p. 24-25.

BRAND, U.; GÖRG, C. Globalización? Desarrollo sostenible como pegamento para el montón de cristalestrizados del neoliberalismo. Ambiente e Sociedade, Campinas, v.5, n.2/v.6, n.1, 2003 (não paginado).

BRASIL. Decreto n. 5.107, de 16 de junho de 2004. Dispõe sobre a 2ª Brigada de Infantaria de Selva e dá outras providências. Diário Oficial [da] República Federativa do Brasil, Brasília, 17 jun. 2004.

BURSZTYN, M. Armadilhas do progresso: contradições entre economia e ecologia. Sociedade e Estado, Brasília, v. X, n. 1. jan./jun. 1995.

CERVO, A. L. Relações internacionais do Brasil: um balanço da era Cardoso. Rev. Bras. Polít. Int., Rio de Janeiro, v. 45, n. 1, p. 5-35, [2002]. Disponível em: <http://www.scielo.br/pdf/rbpi/v45n1/a01v45n1.pdf>. Acesso em: 11 set. 2009. BRASIL. Constituição (1988). Constituição da República Federativa do Brasil: 29. ed. Brasília: Câmara dos Deputados, 2008.

CORAZZA, R. I. Tecnologia e meio ambiente no debate sobre os limites do crescimento: notas à luz de contribuições selecionadas de Georgescu-Roegen. Economia, Brasília, v. 6, n. 2, p. 435-461, jul./dez. 2005. Disponível em: < http:/ / www.anpec.org.br/revista/vol6/vol6n2p435_461.pdf >. Acesso em: 12 abr. 2011. CORTEZÃO, J. O Tratado de Madrid. Ed. fac-similar. Brasília: Senado Federal, 2001.

DEAN, W. A luta pela borracha no Brasil. São Paulo: Nobel, 1989.

EXÉRCITO BRASILEIRO/5º BIS, 2011. Disponível em: < http://www.cfrn5bis. eb.mil.br/unidade/unidade.htm>. Acesso em: 02 mar. 2011.

EXÉRCITO BRASILEIRO. Aprova a diretriz estratégica de gestão ambiental do. Exército Brasileiro. Portaria n. 571, de 06 de novembro de 2001. Boletim do Exército n. 46/2001, Brasília, 18 jul. 2001.

GADELHA, R. M. A. F. Conquista e ocupação da Amazônia: a fronteira Norte do Brasil. Disponível em: <http://www.scielo.br/HYPERLINK "http:/ / www.scielo.br/pdf/ea/v16n45/v16n45a05.pdf"pdf/ea/v16n45/v16n45a05.pdf>. Acesso em: 05 mar. 2007. 
Hemming, J. The Amazon: Land Without History. Tipití: Journal of the Society for the Anthropology of Lowland South America, v. 6: Iss. 1, Article 18, 2008. Disponível em: <http://digitalcommons.trinity.edu/tipiti/vol6/iss1/18>

HOBSBBAWM, E. A era dos extremos, o breve século XX (1914-1991). São Paulo: Companhia das Letras, 1995.

MACHADO, L. de O. R. Desflorestamento na Amazônia brasileira: ação coletiva, governança e governabilidade em área de fronteira. Sociedade e Estado, Brasilia, v. 24, n. 1, p. 115-147, jan./abr. 2009.

MARQUES, A. A. Concepções de defesa nacional no Brasil: 1950-1996. 2001. 153 f. Dissertação (Mestrado em Ciência Política) - Departamento de Ciências Políticas, Instituto de Filosofia e Ciências Humanas, Universidade Estadual de Campinas. Campinas, 2001.

MARTINS FILHO, J. R.; ZIRKER, D. Forças Armadas, Soberania Nacional e Defesa da Amazônia. Estudos de História, Franca, v. 8, n. 1, 2001.

MINISTÉRIO DA DEFESA. Política de Defesa Nacional-1996. Brasília, 1996.

PERI, Enzo Martins (Comandante do Exército). Palestra na Comissão de Relações Exteriores e Defesa Nacional do Senado Federal. Diário do Senado Federal - Suplemento, Brasília: 2007, p. 726. Disponível em: <http://www.senado. gov.HYPERLINK "http://www.senado.gov.br/sf/publicacoes/diarios/pdf/ sf/2007/11/011"br/sf/publicacoes/diarios/pdf/sf/2007/11/011

12007/suplemento/00721.pdf>. Acesso em: 01 out. 2009.

PESCE, E. Í. Forças Armadas e o Orçamento. Revista Marítima Brasileira, Rio de Janeiro, v. 126, n. 04/06, p.103-113, abr./jun. 2006.

RODRIGUES, T.M. S. A infindável guerra americana Brasil, EUA e o narcotráfico no continente. São Paulo em perspectiva, São Paulo, v. 16, n. 2, abr./jun. 2002. Disponível em: < http://www.scielo.br/pdf/spp/v16n2/12116.pdf>. Acesso em: 23 ago. 2009.

SILVA, A. B. Geopolítica na fronteira norte do Brasil: o papel das Forças Armadas nas transformações sócio-espaciais do Estado de Roraima. 2007. 187 f. Tese (Doutorado em Geografia Humana) - Faculdade de Filosofia, Letras e Ciências Humanas, Universidade de São Paulo, São Paulo, 2007.

SILVA, G. do C. e. Conjuntura política nacional: o poder executivo \& geopolítica do Brasil. Rio de Janeiro: José Olympio, 1981. 
SILVA, M. I. C. Amazônia e política de defesa no Brasil após o regime militar: o papel do Programa Calha Norte e do SIVAM-SIPAM. In: VAZ, A. C.; SANTOS, H. E. A. dos; MOREIRA, F. K. (Orgs.). Amazônia: discursos e realidades. Boa Vista: Editora da UFPA, 2008, p. 127-152.

SOARES, T. História da formação das fronteiras do Brasil. Rio de Janeiro: Conselho Federal de Cultura, 1972.

SOUZA, M. Breve história da Amazônia. Rio de Janeiro: Agir, 2001.

STUDART, H. A lei da selva. São Paulo: Geração Editorial, 2006.

THÉRY, Hervé. Situações da Amazônia no Brasil e no Continente. Estudos Avançados (USP), São Paulo, v.19, n. 53, p. 37-49, 2005.

TILIO NETO, P. de. Soberania e ingerência na Amazônia Brasileira. 2003. 143 f. Dissertação (Mestrado em Ciência Política) - Faculdade de Filosofia, Letras e Ciências Humanas, Universidade de São Paulo, São Paulo, 2003.

WEINSTEIN, B. Manaus durante o ciclo da borracha (1875-1920). Rio de Janeiro: Brasiliense, 1998.

ZAVERUCHA, J. Frágil democracia: Collor, Itamar, FHC e os militares (19901998). Rio de Janeiro: Civilização Brasileira, 2000. 
